\title{
Centralidad del Templo 16 durante el Reino de Yax Pasaj en Copán
}

Jorge Ramos

\section{Resumen}

El arte público que aparece en las fachadas de edificios transmite temas complejos, mensajes dirigidos a una amplia audiencia, buscando legitimar la posición del gobernante. Restos de escultura arquitectónica del Clásico Tardío en Copán indican que los edificios desplegaban mensajes particulares ya sea utilizando individualmente, o de manera combinada, una imaginería local maya o extranjera. Las tradiciones extranjeras se identifican con el centro lejano de Teotihuacán en el México Central. Las tradiciones de Teotihuacán están presentes en el sitio desde el Clásico Temprano (430 D.C.), alrededor de los tiempos del fundador K'inich Yax K'uk' Mo'. Yax Pasaj, el último gobernante de la dinastía del fundador, enfatizó esta herencia cultural a gran escala en el Templo 16. El análisis de escultura proveniente del templo resultó en la identificación de 63 motivos diferentes, los cuales revelaron tres temas iconográficos mayores: el edificio como la montaña simbólica tanto como el aposento y resurrección del fundador ancestral; como el lugar del ritual para la conmemoración y restablecimiento de la guerra y el sacrificio humano y; como una representación del universo.

Palabras Clave: Copán, Templo 16, escultura, iconografía, legitimación política.

\section{Abstract}

The public art that appears on the buildings' facades conveys complex topics, messages directed to a wide audience, seeking the legitimization of the ruler's position. Fragments of architectural sculpture from the Late Classic Copan site indicate that the buildings display particular messages either individually, or in a combined manner, by utilizing local maya or foreign imagery. Foreign traditions are related to the distant center of Teotihuacan in Central México. Teotihuacan traditions are present at the site from the early Classic (430 A.C.), around the time of the founder K'inich Yax K'uk' Mo'. Yax Pasaj, last ruler of the founder's 
dynasty, emphasized a large scale cultural heritage on Temple 16. The sculpture analysis from the temple resulted in the identification of 63 different motifs, which revealed three main iconographic themes: the building as a symbolic mountain both for the dwelling and resurrection of the ancestral founder; as the place of ritual for commemoration and reestablishment of war and human sacrifice and; as a representation of the universe.

Keywords: Copan, Temple 16, sculpture, iconography, political legitimation.

Jorge Ramos (arqueologiacopan@yahoo.com), Investigador Asociado ASCOPANIARPACUNA 


\section{INTRODUCCIÓN}

Copán se ubicaba en una zona de transición cultural, un paisaje con interacción multirregional y, en consecuencia, una convergencia de identidades. Este factor detonó el desarrollo de Copán como la capital de una comunidad regional en la orilla sureste del mundo maya. Solamente unos pocos centros mayas pueden compararse con la alta calidad y el profuso arte de los logros que distinguen a Copán del resto del Mundo Maya. Tal como ya se ha reconocido, el arte público que aparece en fachadas de edificios transmite temas complejos, mensajes dirigidos a una amplia audiencia, buscando legitimar la posición del gobernante. Restos de escultura arquitectónica del Clásico Tardío en Copán indican que los edificios desplegaban mensajes particulares ya sea utilizando individualmente o combinada una imaginería local maya o extranjera. Las tradiciones extranjeras se identifican con el centro lejano de Teotihuacán en el México Central. Las tradiciones de Teotihuacán están presentes en el sitio desde los tiempos del Clásico Temprano (430 D.C.), alrededor de los tiempos del fundador K'inich Yax K'uk' Mo' (KYKM). Después de la llegada de esta figura en el año 427 D.C., Copán sufrió transformaciones mayores en los aspectos culturales, políticos y económicos. Aunque los datos arqueológicos (e. g., el análisis óseo) sugieren que él era un maya extranjero del Petén Central (Buikstra et al. 2004: 191-192; Sharer 2003, 2004: 300), la investigación también indica que él era un portador de tradiciones teotihuacanas (Stuart 2000; Taube 2004), rasgo aprovechado por generaciones posteriores de gobernantes. Yax Pasaj, el último gobernante de la dinastía de K'inich Yax K'uk' Mo', enfatizó esta herencia cultural a gran escala en el Templo 16. Además, la imaginería que se despliega en este edificio revela el interés del rey por comunicar conceptos que mantendrían el orden social de Copán tanto sobrenatural como terrenal durante un tiempo de aparente agitación.

El análisis de más o menos unas 2000 piezas de escultura provenientes del templo, resultó en el aislamiento de 63 motivos diferentes; estos revelaron tres temas iconográficos mayores: (A) el edificio como la montaña simbólica tanto como el aposento y resurrección del fundador ancestral, (B) como el lugar del ritual para la conmemoración y restablecimiento de la guerra y el sacrificio humano y $(\mathrm{C})$ como una representación del universo. 


\section{TEMPLO 16: LA EXPRESIÓN DE UNA IDENTIDAD MAYA Y DEL MÉXICO CENTRAL}

El Templo 16 fue dedicado en el año 776 D.C. por el decimosexto gobernante de Copán, Yax Pasaj, en el corazón de la Acrópolis, como el último de una serie de construcciones superpuestas en este punto. Su ubicación prominente, en el espacio central y más importante de la ciudad y sus temas iconográficos, recordando tanto a Teotihuacán como al fundador K'inch Yax K'uk' Mo', convirtieron al Templo 16 en un monumento referente del sitio. Esta estructura figuraba como la empresa suprema por medio de la cual él transmitía un mensaje fuerte de antigüedad, llamando la atención de la memoria social, dirigida a reforzar la identidad de la élite y a validar su autoridad. El templo consiste de una plataforma masiva de diez terrazas con un templo rectangular de dos pisos (véase Figura 1). Fue diseñado para tener su acceso principal por el lado oeste por medio de unas graderías en forma de una "T" invertida y decoradas con bloques gigantescos de escultura. El espacio interior consiste en corredores que se entrecortan en el centro con una banca levantada y otras paredes en su juntura, dando como resultado cuartos orientados hacia los cuatro puntos cardinales. Después de ciertas modificaciones, solamente el cuarto oeste y el espacio más importante continuaron funcionando como tal, manteniendo su tamaño original. Unas gradas que se construyeron en la parte norte del cuarto permitían el acceso al segundo piso, que consistía de un único cuarto $(6.20 \times 3.30$ $\mathrm{mts}$.), orientado este-oeste, con puertas en los lados norte y oeste. El Altar $Q$, al pie de la estructura, completa el programa iconográfico total del edificio. La escultura arquitectónica de este templo ofrece la más diversa y ecléctica composición iconográfica, presentando numerosas representaciones de variados motivos. 


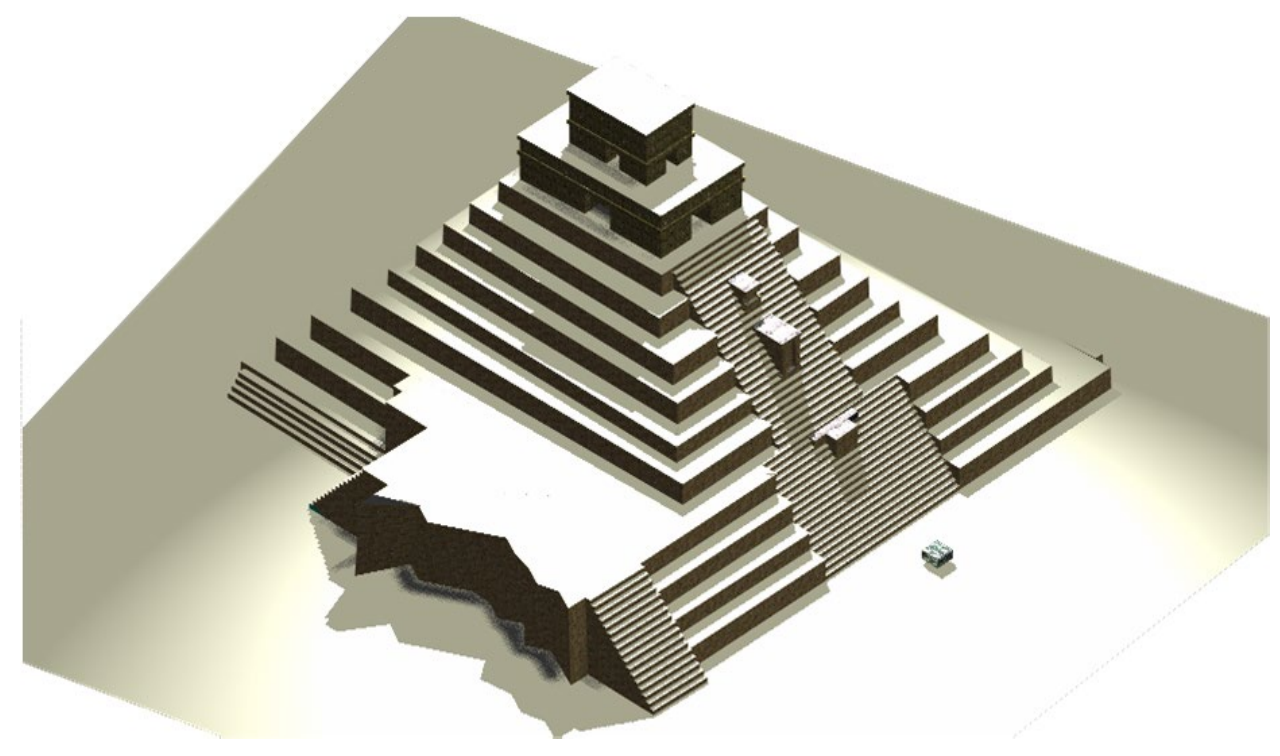

Figura 1: Reconstrucción del Templo 16.

\section{La Montaña Sagrada: un Lugar de Aposento y de Evocaciones a Seres Sobrenaturales}

El Templo 16 es una construcción masiva, la plataforma más alta del núcleo de Copán desde la cual podía verse cualquier lugar en el valle y en las colinas circundantes. Además de sus características físicas, símbolos iconográficos particulares, que decoraban las fachadas, relacionan esta estructura a la montaña sagrada. Mosaicos rectangulares gigantescos representaban las máscaras de Witz en el segundo piso (véase Figura 2). Estas máscaras se esculpieron principalmente en estilo simple de dos dimensiones y se repetían una vez en cada lado del edificio. Estas máscaras están decoradas con rectángulos de semi-glifos a los lados, decorados con signos centrales superiores en forma de un grupo de círculos como un gajo de uvas (signos tun o de piedra) colgando del claustro. Estos paneles tienen a su vez a cada lado medio- círculos rodeados de puntos. Elementos de respiración salen de la boca y un hocico curvo aparece entre los ojos. 


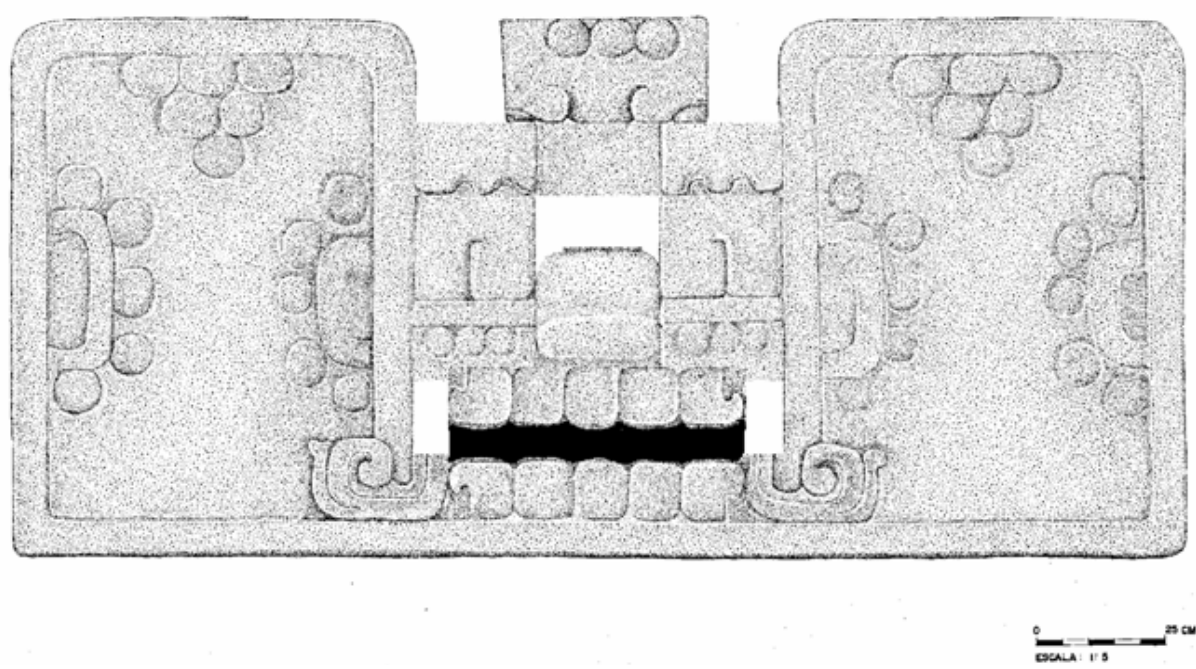

Figura 2: Witz del Templo 16.

El patrón de distribución de la imaginería de Witz alrededor del templo puede que denote simbolismo direccional, un concepto prevalente en el pensamiento religioso de Mesoamérica. Un rasgo especial en el Templo 22 de Copán que expresa la idea de las cuatro montañas sagradas es el juego de Witz apilados en las esquinas del edificio. De la misma manera, el cocodrilo cósmico modelado en estuco detrás de Papagayo, debajo del Templo 26, está decorado con cuatro signos de tun ( Fash 2001: 85) como una referencia a las montañas direccionales. Este simbolismo de la montaña direccional, expresado en arte y en arquitectura espacial también se encuentra relacionado con el paisaje natural y con el comportamiento ritual entre comunidades mayas contemporáneas. En Zinacantán, Chiapas, la gente lleva a cabo rituales asociados con el modelo cuadrilateral. Los zinacantecos realizan rituales de agradecimiento a las cuatro montañas sagradas importantes alrededor del centro ceremonial (Vogt 1969: 602). Las montañas sagradas orientadas a las cuatro direcciones del mundo son un aspecto importante que se observa en la cosmología de los maya Tzeltzal también. Las montañas son rasgos que se reverencian entre los Tzeltzal, quienes creen que cada montaña está habitada por un ancestro (ch'ulel), proveniente de cada uno de los cuatro linajes de la comunidad (Pitarch Ramon 1996:35f-36). 
La identificación de montañas como lugares de aposento de ancestros deificados o dioses fue un concepto religioso que inició un comportamiento ritual entre los mayas clásicos. Este simbolismo se expresa en Copán en monumentos como la Estela B y el Templo 22. El mismo simbolismo de la veneración de ancestros se refleja en el Templo 16. La pared trasera del cuarto al oeste representa a una gigantesca serpiente, sosteniendo en su boca al ancestro K'inich Yax K'uk' Mo' (véase Figura 3). Este mosaico representa una visión después de un ritual de conjuro. Muy similar al Dintel 25 (Estr. 23) de Yaxchilán y a una de las figuras en la Escalinata Jeroglífica de Copán, al ancestro se le representa como un guerrero al estilo teotihuacano en la boca de una Serpiente de Guerra.

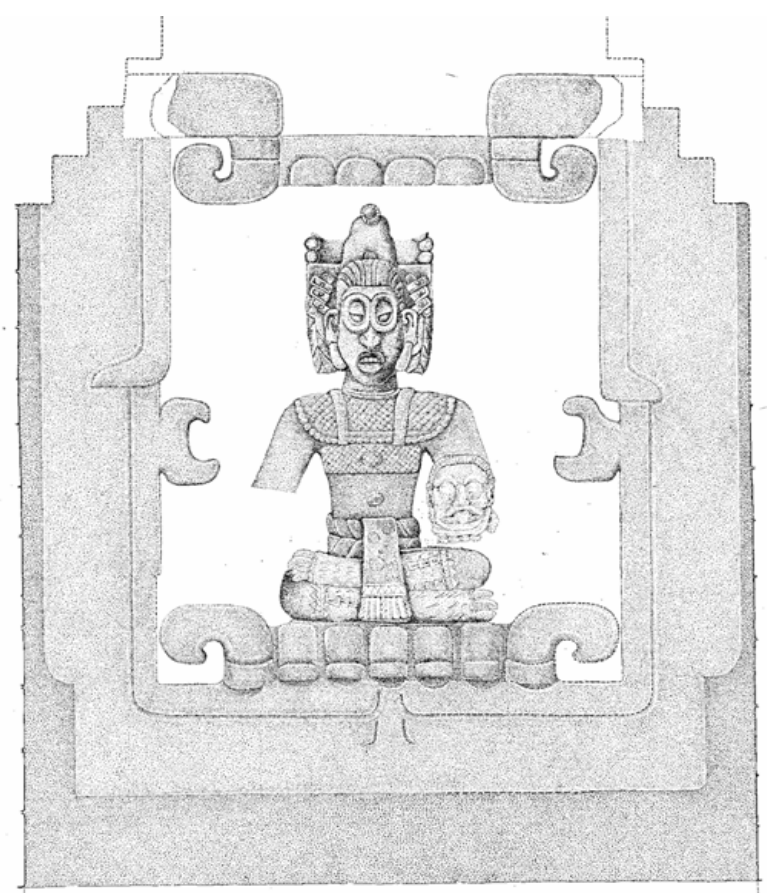

Figura 3: Cuarto Oeste del Templo 16.

El conjuro y comunión con los muertos en la religión antigua maya involucraba ciertos rituales, incluyendo ritos de sangrado o de autosacrificio (Schele y Miller 1986; ver también a McAnany 1995, 1998). Estos rituales se llevaban a cabo en cuartos oscuros de templos, tal como lo sugiere el Dintel 24 de Yaxchilán. En el pensamiento maya contemporáneo, la oscuridad a menudo se relaciona con el 
poder sobrenatural, haciendo de los cuartos oscuros de templos un lugar especial para el contacto con seres sobrenaturales. Esta interpretación se confirmó arqueológicamente en el Templo 16. A finales del siglo XIX, Maudslay informó que un incensario de piedra, decorado con marcas de piedra-tun-formaba parte de un conjunto ceremonial dentro del cuarto occidental. La iconografía interna y los artefactos rituales, como evidencia para el fuego de ofrendas, reciben apoyo de los elementos en el techo, que representan llamas, sobre el edificio. Iconografía paralela similar se ha encontrado en el Templo Rosalila (Taube 2000, 2004) y la vasija que se encontró en la tumba Margarita, al que se le ha llamado "El Deslumbrado". Junto con la iconografía del Templo 16, estas muestras recuerdan la quema ritual conectada con la veneración del fundador. El Marcador Motmot, la tapadera de tumba que se encontró dentro del Templo 26, hace una asociación explícita entre el fundador y lo que nosotros caracterizaríamos como un "santuario de fuego". En este momento, al nombre de KYKM le sigue un título que lo componen la cabeza de un murciélago y un templo en llamas. Como lugares para la realización de rituales, incluyendo el conjuro de dioses y ancestros, los templos eran reinos místicos y sobrenaturales para los antiguos mayas.

El Templo 16 puede también tomarse como el lugar de vivienda del fundador KYKM; la unión de un mosaico pequeño reveló información apoyando esta idea (véase Figura 4). Este motivo cuasi-emblemático se parece con el glifo de bulto cruzado que se encuentra en muchos centros mayas y el que se ha interpretado como el topónimo para la casa de origen (Witenaah), edificio asociado con Teotihuacan (Stuart 2004:235-237; 2005:377). El trabajo epigráfico que han realizado Linda Schele y David Stuart también identificó el motivo de bulto cruzado con el fundador (Schele 1986, 1992; Stuart y Schele 1986). El Templo 16, ubicado en el centro de la Acrópolis de Copán, puede que represente la Casa de Origen como "la conmemoración explícita de la fundación dinástica", el lugar distante donde KYKM tomó el K'awiil o donde fue investido con estatus de realeza. Los asociados Altar Q y su entierro, al pie del Templo 16 también apoyan esta interpretación. 


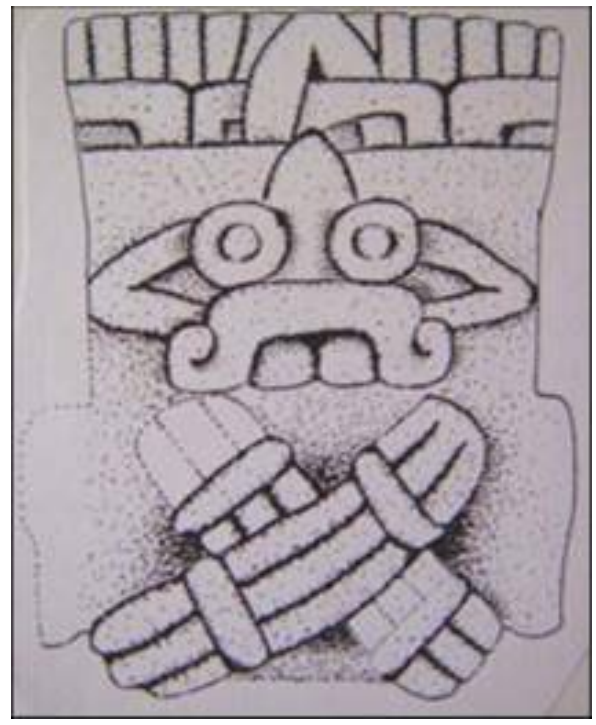

Figura 4: Glifo del Fundador, Templo 16.

El concepto de montañas y cuevas como casa para los ancestros es una idea religiosa antigua y muy diseminada por Mesoamérica, desde los olmecas hasta el presente (Maya-Tzoltzil, Tzeltzal, Quiché) (Vogt 1999; B. Tedlock 1992). Dentro de la escritura y el arte maya, a las cuevas también se les identifica con aperturas o portales que llevan al inframundo. Algunos motivos como imágenes mortíferas pueden también identificar a las cuevas con el inframundo. Sobre sus puertas, el Templo 16 desplegaba piezas escultóricas grotescas y únicas que servían como sostenedores de cuerdas. La ubicación y los rasgos de estas piezas indican que la intención era marcar los cuartos del templo como si fuesen espacios de otro mundo. Su posición sobre las puertas puede que por eso se refieran a aperturas 0 portales hacia cuevas aterrorizantes dentro de montañas metafóricas.

\section{El Templo 16 y la Expresión del Cosmos}

Las culturas mesoamericanas expresaban ideas cosmológicas sobre su mundo físico y los mayas no fueron excepción. Ellos creían en una dimensión vertical dividida en tres capas básicas: el inframundo ocupaba el nivel en la base, la tierra ocupaba el nivel medio y el cielo el nivel superior. Seres particulares habitaban cada uno de estos niveles. La dimensión horizontal del mundo, al contrario, se representaba con esquinas inter-cardinales, enmarcando el axis mundi central 
y punto de partida (Freidel et al. 1f993; Manzanilla 2000:92; Taube 1998, 2003). Este modelo quincuence del universo es un rasgo constante en el pensamiento mesoamericano desde los olmecas tempranos (Taube 1988).

En el Copán del Clásico Tardío, los mayas presentaron este concepto del mundo a través de diferentes formas y medios. Una muestra se encuentra en la imaginería del Templo 16. Imágenes particulares se distribuyeron espacialmente alrededor del edificio para representar explícitamente un cosmograma en dos dimensiones. Esculturas mosaicas elaboradas representando figuras robustas parcialmente sentadas, se repetían dos veces en las fachadas norte y sur del segundo piso. Representada en la apariencia de un guerrero teotihuacano, esta figura es casi una copia del retrato de KYKM en el Altar Q. Llevando anteojeras, sandalias típicas mayas y una faja pesada de mecate, el guerrero lleva en su brazo izquierdo un escudo cuadrado mexicano, decorado con la imagen de la Serpiente de la Guerra. Esta figura también se parece con los Tlalocs esqueléticos que aparecen en las gradas del templo. El patrón quincuence se completa con la quinta figura dentro del cuarto occidental del edificio, más o menos al centro del cosmograma. Así como los Tlalocs guerreros direccionales del Templo 16, la escena pictórica del Códice Borgia (página 27), también representa a cuatro Tlalocs antropomorfos direccionales, alrededor de otro central. Una vasija del Clásico Temprano de la costa sur de Guatemala (Cotzumalhuapa) tiene la misma composición iconográfica con cuatro cabezas de Tlaloc en las cuatro partes del mundo, rodeando una más grande en el centro. Un patrón similar, con imágenes en figura completa, se observa en la pintura interior de una vasija de piedra del Postclásico, proveniente de Tizapán, México.

El modelo cuatrilobulado en discusión también aparece en la distribución en que el primer piso del Templo 16 se confeccionó. Sobre la décima terraza de la plataforma se colocaron cuatro bloques masivos de piedra, creando cuatro cuartos o corredores orientados hacia los cuatro puntos cardinales, representando una gigantesca Cruz K'an. El siguiente paso en la construcción del edificio fue subir las paredes en el centro para separar o crear cuartos individuales. Suficientemente interesante es el hecho que, durante este proceso de construcción, los mayas ubicaron en el cuarto occidental, aproximadamente al centro del edificio, una banca y una pared llevando un elegante mosaico esculpido, representando una cabeza hendida de serpiente, de la cual sale KYKM, como si viniera del inframundo.

La Cruz K'an, además de otros posibles significados, también implica ideas relacionadas con centralidad y, consecuentemente, con el cosmos (Taube 2000, 2004). El plan del piso, juntamente con la iconografía del cuarto occidental del 
Templo 16, expresa ideas cosmológicas, una metáfora del universo en sus divisiones verticales y horizontales. La figura central que se mencionó anteriormente está representada como el árbol cósmico, el centro del mundo metafóricamente resucitando desde el inframundo, materializado en el centro de la Cruz K'an. El simbolismo alrededor de la Cruz K'an y su identificación con la centralidad era muy difusa en Mesoamérica. Un escudo mosaico ceremonial azteca, que está en exhibición en el Museo Británico, expresa este concepto. Este objeto redondo del Postclásico muestra un elemento central de turquesa-probablemente un disco de sol-del cual rayos apuntan hacia las cuatro direcciones. Sobre este disco aparece el árbol del mundo, al que se le interpreta como levantándose del centro del universo, con una cabeza antropomorfa en su cima. De especial significado es la serpiente ondulante que se levanta desde el inframundo, pasando por el cuatrilobulado y de esa manera unificando el inframundo, la tierra y los cielos. Esta composición es sorprendentemente similar a la escena que aparece en la Estela 4 del Preclásico Tardío en TakalikAbaj. El monumento presenta una serpiente ondulada comparable, saliendo de las mandíbulas abiertas con un signo del sol en el centro y una probable cabeza ancestral en la boca.

Los cuatro dioses direccionales que encierran la composición central del disco azteca en el primer lado recuerda a los cuatro Pauahtunes, en algún momento colocados en las cuatro esquinas, sosteniendo el cielo, en el Templo 11 de Copán. Aunque solamente quedan dos de estos pauahtunes, no podemos desechar la posibilidad del modelo cuatrilobulado, tal como aparece en la disposición del mismo edificio. Las bancas en Copán, durante el reino de Yax Pasaj, quien mandó a construir el Templo 11, usualmente aparecen sostenidas por cuatro de estos seres mitológicos (Plank 2004: fig. 5.42a).

El concepto de centralidad estaba ligado al gobierno en el pensamiento mesoamericano. Esta relación se enfatiza en las estelas reales y sus cámaras bajo tierra en Copán. Como ofrendas dedicatorias, los escondites se depositaban en criptas espacialmente arregladas en la forma de una Cruz K'an sobre la cual se erigían las estelas. Estos monolitos, incluyendo las Estelas A, C, I, M y 1 (ver Gordon 1896, Vol. 1: 35-36) representaban a gobernantes como personificaciones del axis del mundo, parado sobre un micro-modelo del cosmos (Newsome 2000; Witmore 1998:141). Puestos en el centro del mundo, los gobernantes eran una referencia explícita al Dios del Maíz y su resurrección como el árbol del mundo primordial. Por medio de esta idealizada personificación, los gobernantes mayas se convertían en intermediarios convenientes entre los reinos terrestre y celestial. La escena en una vasija maya del Clásico Tardío representa un paralelo cercano 
al concepto de los gobernantes parados en patrones quincuences. En esta vasija aparece K'awiil, el dios maya patrón de los gobernantes sentado sobre un trono decorado con el motivo de la Cruz K'an.

\section{Guerra y Sacrificio Humano con Conexión Teotihuacana}

El sacrificio humano en combinación con la guerra fue muy común entre los mayas del Clásico (Schele 1984:43-45; Webster 1977, 1998) y un aspecto fundamental de la religión teotihuacana (Ver Sugiyama 1996, 2000, 2005). La iconografía del Templo 16 refleja esta conjunción de temas, a través de una variedad de motivos.

\section{La Lechuza de la Guerra}

La sección superior del primer piso representa a una lechuza convencional (véase Figura 5). Esta imagen se repitió ocho veces con una representación en cada una de las cuatro esquinas y en cada una de las fachadas del edificio. Con plumas estilizadas extendidas, una cola amarrada proyectándose hacia arriba y los garfios más bajos expuestos, esta lechuza parece estar en movimiento. Las alas llevan el signo mexicano del año, muy similar a la deidad Tlaloc de la guerra del Complejo de Monjas del Clásico Terminal en Uxmal. Una vasija maya del Clásico Tardío también muestra una lechuza natural de cuerpo completo con símbolos del año a los lados parada sobre un par de ojos parecidos a anteojeras. El pájaro sostiene una máscara de Tlaloc adornada con un tocado que lleva signos del año. La lechuza del Templo 16 también lleva en la frente un signo del año muy estilizado, similar a otras lechuzas en el arte maya y teotihuacano, como los que aparecen en la Estela 9 de Piedras Negras, en Tetitla (pórtico 11), en Atetelco (Patio Blanco) y en los murales de Tepantitla. Tanto para la gente teotihuacana como para la maya, el signo del año era un símbolo de gobierno, liderazgo militar y sacrificio. 


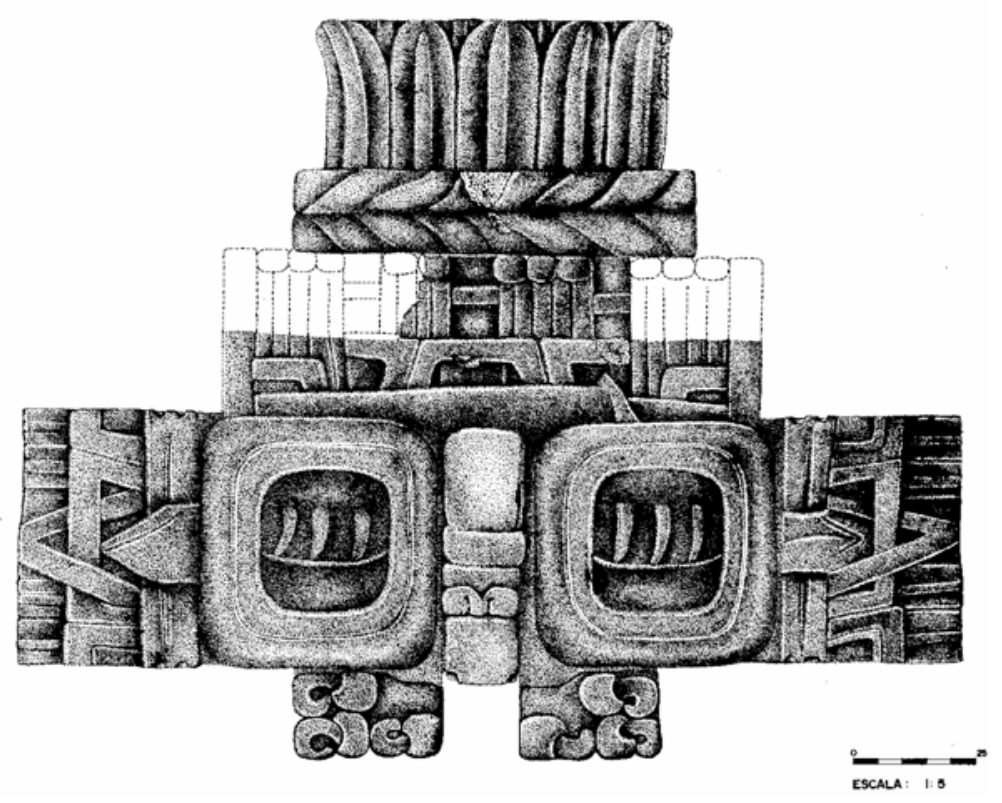

Figura 5: Lechuza del Templo 16.

Un motivo trilobulado, probablemente refiriéndose a un corazón sangrante aparece atrapado en el pico de la lechuza. Esta imaginería significa sacrificio ritual, y en Copán, aparece solamente en el Templo 16. Un paralelo iconográfico aparece en la Estela 9 de Piedras Negras. Este monumento representa una lechuza descansando sobre el tocado del gobernante, con un corazón sangrante cayendo del pico de la lechuza. Corazones sangrando también aparecen en una variedad de contextos en Teotihuacan, involucrando seres zoomorfos y antropomorfos. Una figurilla moldeada en barro, por ejemplo, representa un pájaro, muy posiblemente una lechuza devorando un corazón del cual solamente es visible la sangre goteando. Una vasija pintada demuestra un quetzal detrás de un corazón sangrando, atrapado dentro de un cartucho emplumado. Una pared pintada del conjunto Tetitla representa una escena vívida de un águila realizando un sacrificio que sería dramática desde el punto de vista de un espectador. Una composición similar se encuentra en la tapadera de una vasija del Clásico Tardío del Grupo 6C-XVI en Tikal, Representa dos águilas con corazones humanos completos envueltos en sangre, atrapados en los picos de las águilas como una alusión explícita al ritual de sacrificio. 
Además de aves, otros animales como coyotes, serpientes emplumadas, Serpientes de Guerra y jaguares aparecen asociados con el sacrificio de corazón en Teotihuacan. Por ejemplo, una pintura mural actualmente en exhibición en el Museo de San Francisco despliega dos coyotes, quizá pumas, devorando a un venado. Una Serpiente de Guerra aparece en un mural de la Zona 2 con tres corazones en la boca, uno de ellos sangrando. Además, en el Patio Blanco en Atetelco, jaguares vomitan corazones sangrando. Aparece también allí una serpiente emplumada arqueada en el mismo contexto de sacrificio de corazón.

La iconografía de Teotihuacán incluye también figuras antropomorfas y deidades enfatizando temas militares y de sacrificio. Un águila guerrera se encuentra en la Zona 5 cercando un corazón humano. Un mural del Pórtico 11, del conjunto Tetitla, representa a otro guerrero a manera de Serpiente Guerrera, llevando armas, con un pectoral de guerra de lechuza y tocado adornado con tres corazones. Además, una vasija representa a otro guerrero con vestimenta similar llevando un tocado de Serpiente de Guerra, asociado con un juego similar de corazones.

La variedad de seres como lechuzas, águilas y jaguares y contextos identificados con temas militares y de sacrificio puede que indiquen la participación de algún tipo de órdenes militares dentro de la religión teotihuacana. Gobernantes mayas también aparecen asociados con corazones al estilo teotihuacano en monumentos conmemorando eventos de guerra y de sacrificio. El Gobernante 12 de Copán aparece en la Estela 6 con corazones sangrantes en su faja y sandalias. El Gobernante A de Tikal también aparece en la Estructura 5D-57 con un corazón sangrante en su frente. Corazones similares decoran la vestimenta de un guerrero de Xelha, Quintana Roo, quien lleva un tocado a la imagen de la Serpiente de Guerra con la probóscide de la mariposa. Los gobernantes de Piedras Negras aparecen en las Estelas 7 y 8 llevando bastones de sacrificio con motivos trilobulados ligados. Finalmente, un mural de Cacaxtla representa guerreros en batalla asociados con corazones sangrando. En comunidades clásicas mayas este comportamiento de ritual tenía un aspecto político. Estaba ligado al acto de gobernar y a la validación del poder.

\section{CONCLUSIONES}

En resumen, el Templo 16 presenta un programa iconográfico híbrido, combinando conceptos locales mayas y tradiciones de imaginería del México Central. La imaginería, que incluye al monstruo Witz, serpientes de visiones y motivos de fuego, 
como también artefactos arqueológicos como incensarios de piedra, identifica al edificio como una montaña-cueva metafórica y un santuario de fuego, el lugar de aposento y de ritual para el conjuro del ancestro KYKM. Además, imágenes como la lechuza marcial aluden a guerra, sacrificio humano y muerte. La guerra y el sacrificio eran conceptos fundamentales en la religión maya, utilizados por el rey para cumplir con su supremo papel religioso y político de ordenar y perpetuar la estructura social y el cosmos. Esta imaginería, aunque presentada en un estilo maya innovador, está muy de acuerdo con los conceptos y tradiciones de Teotihuacán, lugar histórico y legendario con fuertes conexiones antiguas con Copán. La imaginería y el plan del Templo 16 hacen del edificio un micro universo, un lugar de renacimiento y de resurrección.

\section{BIBLIOGRAFÍA}

- Buikstra J. E., Price T.D., Wright L.E., Burton J.A. (2004). Tombs from the Copan Acropolis: A Life History Approach. En E. E. Bell, Understanding Early Classic Copan (págs. 191-214). Philadelphia: University of Pennsylvania Museum of Archaeology.

- Fash, W. L. (2001). Scribes, Warriors and Kings: The City of Copan and the Ancient Maya. London: Thames and Hudson.

- Gordon, B. G. (1896). Prehistoric Ruins of Copan, Honduras: A Preliminary Report of the Explorations by the Museum, 1891-1895 Memoirs of the Peabody Museum of American Archaeology and Ethnology vol. 1, no. 1. Cambridge : Harvard University.

- Manzanilla, L. (2000). The Construction of the Underworld in Central Mexico: Transformations from the Classic to the Postclassic. En D. Carraco, Jones L., Sessions S., Mesoamerica's Classic Heritage: From teotihuacan to the Aztecs (págs. 87-116). Boulder: University Press of Colorado.

- McAnany, P. A. (1995). Living with the Ancestors: Kinship and Kingship in Ancient Maya Society . Austin: University of Texas Press.

- McAnany, P. A. (1998). Ancestors and the Classic Maya Build Enviroment. En S. D. Houston, Functions and Meaning in Classic Maya Architecture (págs. 271-298). Washington : Dumbarton Oaks. 
- Newsome, E. (2000). Trees of Paradise and Pillars of the World: The Serial Stelae Cycle of "18-Rabbit-God K," King of Copan. Austin: University of Texas Press.

- Pitarch Ramon, P. (1996). Ch'ulel: Una Etnografía de las Almas Tzetzales. México : Fondo de Cultura Económica.

- Schele, L. (1984). Human Sacrifice among the Classic Maya. En E. H. Boone, Ritual Human Sacrifice in Mesoamerica (págs. 7-48). Washington : Dumbarton Oaks Research Library and Collection.

- Schele, L. (1986). The Founders of Lineages at Copan and Other Maya Sites. Copan Mosaics Project and Instituto Hondureño de Antropología e Historia.

- Schele, L. (1992). The Founders of Lineages at Copan and Other Maya Sites . Ancient Mesoamerica, 135-145.

- Schele L., Miller M. (1986). The Blood of Kings; Dynasty and Ritual in Maya Art. Forth Worth: Texas Kimbal Art Museum.

- Sharer, R. J. (2003). Tikal and The Copan Dynastic Founding. En J. A. Sabloff, Tikal: Dynasties, Foreigners and Affairs of State, Advancing Maya Archaeology (págs. 319-354). Santa Fe: School of American Research Press.

- Sharer, R. J. (2004). External Interactions at Early Classic Copan . En E. E. Bell, M. Canuto, R.J. Sharer, Understanding Early Classic Copan (págs. 297318). Philadelphia: University of Pennsylvania Museum of Archaeology and Anthropology.

- Stuart, D. (2000). The Arrival of Strangers: Teotihuacan and Tollan in Classic Maya History . En D. Carrasco, Mesoamerica's Classic Heritage: From Teotihuacan to the Aztecs (págs. 465-513). Boulder : University Press of Colorado.

- Stuart, D. (2005). A Foreign Past: The Writing and Representation of History on a Royal Ancestral Shrine at Copan . En E. W. Andrews, W. Fash, Copan: the History of an Ancient Maya Kingdom (págs. 373-395). Santa Fe, Oxford: School of American Researh, James Currey.

- Stuart D., Schele L. (1986). Interim Report on the Hieroglyphic Stair of structure 26, Copan Note 17. 
- Sugiyama, S. (1996). Mass Human Sacrifice and Symbolism of the Feathered Serpent Pyramid in Teotihuacan, México. Disertación Doctoral, Arizona State University.

- Sugiyama, S. (2000). Teotihuacan as an Origin for Posclassic Feathered Serpent Symbolism . En D. Carrasco, L. Jones, S. Sessions. Mesoamerica's Classic Heritage: From Teotihuacan to the Aztecs (págs. 117-144). Boulder: University of Colorado Press.

- Sugiyama, S. (2005). Human Sacrifice, Militarism, and Rulership: Materialization of State Ideology at the Feathered Serpent Pyramid, Teotihuacan. Cambridge : Cambridge University Press.

- Taube, K. A. (1988). The Ancient Yucatec New Year Festival: The Liminal Period in Maya Ritual and Cosmology . Disertación Doctoral: Yale University.

- Taube, K. A. (1998). The Jade Hearth: Centrality, Rulership, and the Classic Maya Temple. En S. D. Houston, Function and Meaning in Classic MAya Architecture (págs. 427-478). Washington : Dumbarton Oaks.

- Taube, K. A. (2000). The Stair Block Sculptures of Structure 10L-16, Copan, Honduras: Fire and the Evocaction and Resurrection of K'inich Yax K'uk Mo'. 65 Reunión Anual de la Sociedad de Arqueología Americana : Filadelfia.

- Taube, K. (2003). Ancient and Contemporary Maya Conceptions about the Field and Forest . En A. G. Pompa, Three Millennia at the Human-Wildland Interface (págs. 461-92). New York : Haworth Press.

- Taube, K. A. (2004). Structure 10L-16 and its Early Classic Antecedents: Fire and the Evocation and Resurrection of K'inich Yax K'uk'Mo'. En E. E. Bell, M. Canuto, R.J. Sharer, Understanding Early Classic Copan (págs. 265298). Philadelphia: University of Pennsylvania Museum of Archaeology and Anthropology.

- Tedlock, B. (1992). Time and the Highland Maya. University of New Mexico Press.

- Vogt, E. Z. (1969). Zinacantan: A Maya Community in the Highlands of Chiapas. Cambridge: The Belknap Press of Harvard University.

- Vogt, E. Z. (1999). Maya Sacred Mountains . Manuscrito en posesión del autor. 
- Webster, D. (1977). Warfare and the evoluction of Maya Civilizations. En R. Adams, The Origins of Maya Civilization (págs. 335-372). Albuquerque: University of New Mexico Press.

- Witmore, C. L. (1998). Sacred Sun Centers . En R. F. Townsend, Ancient West Mexico: Art and Archaeology of the Unknown Past (págs. 137-149). Thames and Hudson, The Art Institute of Chicago. 